\title{
Para reconsiderar la estrategia "reconcentración de escuela” planteada por la SEP
}

\section{To reconsider the strategy "re-concentration of school" proposed by the SEP}

En el Comunicado 493, publicado el 19 de noviembre de 2016 en el marco de la "Estrategia de inclusión y equidad", el secretario de Educación Pública, Aurelio Nuño Mayer, anunció que a principios de 2017 se daría a conocer el "Plan de reconcentración de escuelas". Aunque el Comunicado no especifica en qué consiste dicha reconcentración, se sabe que se trata de trasladar diariamente al alumnado de escuelas multigrado a otras de organización completa, cuando las primeras se ubiquen en un radio de dos kilómetros de estas.

En dicho Comunicado se plantean dos razones para fundamentar una decisión de esa naturaleza, ambas relacionadas con la eficiencia del gasto:

1. “... porque de 200 mil planteles de educación básica, 100 mil concentran solo 14 por ciento de la plantilla escolar en localidades dispersas, con los peores resultados y la menor inversión”.

2. “...se tendrá un gasto más eficiente, y se beneficiará a los alumnos en planteles con organización completa, con educación de calidad y con todos sus profesores" (SEP, 2016).

Según información ofrecida por el subsecretario de Educación Básica, Javier Treviño Cantú, el Plan de reconcentración de escuelas se está piloteando actualmente en San Luís Potosí y Campeche.

Es importante tener presente que la escuela multigrado fue la manera como diferentes países organizaron originalmente sus sistemas educativos, y no fue sino hasta mediados del siglo XIX que se generalizó la organización en grupos de estudiantes de edades 
similares, con el propósito de que fuera posible "atender a grandes cantidades de alumnos en forma eficiente" (Martínez, 2006: 19). En los países de ingresos altos, la tendencia se inclinó a tener todas las escuelas con una organización completa, transportando al alumnado que habitaba en zonas rurales hacia las urbanas. Por su parte, los países de ingresos medios y bajos -como Méxicotendieron a mantener escuelas de organización completa en las zonas urbanas y escuelas multigrado en las localidades rurales y dispersas, para ampliar la cobertura a bajo costo (ibid.).

Ahora bien, es notable que, en el Comunicado, la SEP presenta argumentos vinculados con la eficiencia del gasto, pero ahora en sentido contrario a la historia del multigrado. Adicional a lo anterior, llama la atención que no esgriman consideraciones pedagógicas, culturales, sociales ni económicas que respalden el Plan de reconcentración.

Las escuelas multigrado son aquellas en las que los docentes atienden al alumnado de dos o más grados de manera simultánea en una misma aula. Estas escuelas se caracterizan por estar ubicadas en zonas de altos niveles de pobreza, con condiciones escolares básicas inadecuadas, sin acompañamiento ni formación docente específica, y donde los docentes están en condiciones de aislamiento; todo ello ha redundado en los bajos niveles de logro escolar de sus alumnos. No obstante lo anterior, en estas escuelas se presentan condiciones propicias para pedagogías activas y con una intensa interacción social, con estrategias de aprendizaje colaborativo y facilidad de integración del entorno comunitario, todo lo que permite que el alumnado aprenda de manera significativa debido al continuo entre el aprendizaje académico en la escuela y el uso cotidiano del mismo en la localidad. Cabe destacar, además, que las condiciones de migración y movilidad de la población rural demandan estrategias pedagógicas flexibles, justo como las que han desarrollado los métodos y modelos multigrado.

Las escuelas multigrado, de las cuales muchas son indígenas y son todas las del Conafe, tienen importancia social en las comunidades donde se encuentran ubicadas, pues las familias las perciben como suyas, además de que son espacios usados para diversas actividades socio-culturales, deportivas y recreativas. Estas escuelas contribuyen al arraigo de la gente en sus comunidades, 
el cual se da, entre otras cosas, porque atraen la presencia de instituciones que proveen servicios públicos, con lo cual se posibilita el desarrollo de las zonas rurales (vitales para el sostenimiento del conjunto de la población, pues la vida en las ciudades depende de las zonas rurales, ya que es allí donde se produce el alimento y el agua).

Ahora bien, diversas evaluaciones (Martínez, 2006; Muñoz, Márquez, Sandoval y Sánchez, 2004; Trevińo y Treviño, 2004) muestran que en las escuelas ubicadas en zonas rurales marginadas, donde se encuentra una inmensa mayoría de las escuelas indígenas, los resultados de aprendizaje de los estudiantes están muy por debajo de los obtenidos por sus pares de escuelas públicas urbanas. Pero se ha documentado con suficiencia que estos resultados no obedecen a la condición de ser o no modalidad multigrado, sino a la situación estructural de las escuelas y a la marginación social y económica de las familias y comunidades donde estas se localizan; incluso el Comunicado reconoce la menor inversión en esas escuelas (“... con los peores resultados y la menor inversión”). Según la Red de Investigación de Educación Rural, "La infraestructura escolar, dotación de materiales didácticos, la gestión escolar y el acompańamiento pedagógico son débiles en las escuelas rurales". Es debido a lo anterior que "A diferencia de lo que debería ocurrir, las escuelas no compensan las desventajas que representa el contexto de los hogares más pobres para los alumnos que provienen de ellos, sino que más bien las refuerzan ya que los alumnos que tienen circunstancias más desfavorables en el hogar son atendidos en escuelas de mayores carencias" (INEE, 2007: 120).

Sin soslayar la importancia de la escuela en el aprendizaje, es menos probable que el alumnado de aquellas rurales e indígenas tenga buenos resultados de logro académico cuando sus planteles están en condiciones desfavorables de infraestructura y equipamiento; además de que "En buena parte de las escuelas multigrado se trabaja sin una metodología propia y los maestros deben adaptar contenidos, materiales y evaluaciones diseñados para escuelas regulares (urbanas)" (Red de Investigación de Educación Rural, Conacyt, 2016). 
Por eso esbozamos algunas consideraciones a tener en cuenta para no tomar la decisión de "reconcentración".

- El aumento del riesgo al que estarán sometidas las niñas y nińos debido a su traslado diario, en particular en las zonas montañosas.

- El desgaste al que se verán sometidos al invertir tiempo valioso en el desplazamiento diario.

- La disminución de la participación social en las escuelas debido a la distancia que tendrán que remontar los padres y madres de familia para asistir a eventos que los convoquen e involucren y al desconocimiento que tendrán las y los docentes acerca de la situación familiar de su alumnado. Se sabe que su aprendizaje también está relacionado con la información que los maestros poseen de sus alumnos/as en los planos personal y familiar.

- La imposibilidad de brindar alimentación desde la organización familiar a sus hijas e hijos mientras están en la escuela.

- La mayor discontinuidad entre la cultura de la escuela y el hogar, con especial énfasis en lo que respecta a las lenguas mexicanas.

Por último, sugerimos que, a cambio de la "reconcentración", haya una atención específica y pertinente al fortalecimiento de las escuelas multigrado. Algunas medidas particulares son:

- Que haya dentro de la formación inicial del magisterio un tramo exclusivo y particular para estudiar el multigrado, su filosofía, sus características pedagógicas y didácticas, el rol del docente y del alumnado, la forma de organización de los espacios, los tiempos, el mobiliario, el uso de los materiales educativos, entre otras.

- Que exista seguimiento y acompañamiento de apoyo técnico pedagógico especializado para los y las maestras que trabajen en estas escuelas.

- Que se descargue de lo administrativo a las y los docentes de escuelas multigrado y que estas labores sean asumidas por otras instancias del sistema.

- Materiales educativos apropiados que permitan el aprendizaje 
autónomo y colaborativo propio de la modalidad multigrado. Igualmente, un mobiliario que permita el desplazamiento y organización en equipos de trabajo.

- Tomar en cuenta experiencias mexicanas probadas como el Programa de Aprendizaje Multigrado en Puebla (Mejía et al., 2016) y las Redes de tutoría en varios lugares de la república desde la década pasada y, más recientemente, en CONAFE (Azuma, 2015; López, 2016).

\section{REFERENCIAS BIBLIOGRÁFICAS}

Azuma, A. "Avances y logros de la telesecundaria en México", Subsecretaría de Planeación y Evaluación de Políticas Educativas, México, SEP, Mimeo, 2015.

INEE. La educación para poblaciones en contextos vulnerables, México, INEE, 2007 Disponible en: http://publicaciones. inee.edu.mx/buscadorPub/P1/D/215/P1D215.pdf. Fecha de consulta, 05 de enero de 2017.

López, D. "La relación tutora y la mejora del aprendizaje", en Revista de evaluación para docentes y directivos, RED, 03, enero-abril, México, 2016, pp. 6-21.

Martínez F. "Las primarias comunitarias y su desempeño. Consideraciones a partir del estudio comparativo 2000-2005 del INEE", en Cuaderno No. 23, México, INEE, 2006.

Mejía, F., Argándar, E., Arruti, M., Olvera, A., y Estrada, M. "Programa de Aprendizaje en Multigrado: una experiencia de mejora educativa en el estado de Puebla", en Revista Latinoamericana de Estudios Educativos, vol. XLVI, núm. 3, julio-septiembre, 2016, pp. 111-135.

Muñoz, C., Márquez, A., Sandoval A., Sánchez, H. "Factores que influyen en el logro académico de los estudiantes de primaria en México, 1998-2002", en Cuaderno No. 2, México, INEE, 2004.

Red de Investigación de Educación Rural, México, Conacyt, 2016. Disponible en: http://conacyt.gob.mx/index.php/ carteles/12913-red-educacion-rural/file. Fecha de consulta, 05 de enero de 2017. 
Trevińo, E. y Treviño. G. "Estudio sobre las desigualdades educativas en México: la incidencia de la escuela en el desempeño académico de los alumnos y el rol de los docentes", en Cuaderno No. 5, México, INEE, 2004.

Secretaría de Educación Pública. Comunicado 493, México, SEP, 2016. Disponible en: https://www.gob.mx/sep/prensa/ comunicado-493-anuncia-nuno-mayer-reconcentracionde-escuelas-100-mil-planteles-en-comunidades-dispersas-concentran-14-por-ciento-de-estudiantes. Fecha de consulta, 05 de enero de 2017. 